This is a post-peer-review, pre-copyedit version of an article published in Nature Human Behaviour. The final authenticated version is available online at:

[https://www.nature.com/articles/s41562-019-0815-z]

\title{
A large-scale test of the link between intergroup contact and support for social change
}

\section{Authors:}

Tabea Hässler*1, Johannes Ullrich ${ }^{1}$, Michelle Bernardino ${ }^{2}$, Nurit Shnabel ${ }^{3}$, Colette Van Laar ${ }^{4}$, Daniel Valdenegro ${ }^{5}$, Simone Sebben ${ }^{1}$, Linda R. Tropp ${ }^{6}$, Emilio Paolo Visintin ${ }^{7,8}$, Roberto González ${ }^{2}$, Ruth K. Ditlmann ${ }^{9}$, Dominic Abrams ${ }^{10}$, Hema Preya Selvanathan ${ }^{6,11}$, Marija Brankovic $^{12}$, Stephen C. Wright ${ }^{13}$, Jorina von Zimmermann ${ }^{14}$, Michael Pasek ${ }^{15,16}$, Anna Lisa Aydin $^{17}$, Iris Žeželj ${ }^{18}$, Adrienne Pereira ${ }^{7}$, Nóra Anna Lantos ${ }^{19}$, Mario Sainz ${ }^{20,21}$, Andreas Glenz $^{1}$, Hana Oberpfalzerová ${ }^{22}$, Michal Bilewicz ${ }^{23}$, Anna Kende ${ }^{19}$, Olga Kuzawinska ${ }^{23}$, Sabine Otten ${ }^{24}$, Edona Maloku ${ }^{25}$, Masi Noor ${ }^{26}$, Pelin Gul ${ }^{27}$, Jessica Pistella ${ }^{28}$, Roberto Baiocco $^{28}$, Margareta Jelic ${ }^{29}$, Evgeny Osin ${ }^{30}$, Orly Bareket ${ }^{3}$, Dinka Corkalo Biruski ${ }^{29}$, Jonathan E. Cook ${ }^{31}$, Maneeza Dawood ${ }^{32}$, Lisa Droogendyk ${ }^{33}$, Angélica Herrera Loyo ${ }^{34}$, Kaltrina Kelmendi ${ }^{35}$, \& Luiza Mugnol Ugarte ${ }^{36}$.

\section{Affiliations:}

1 Department of Psychology, University of Zurich, Zurich, Switzerland

2 School of Psychology, Pontificia Universidad Católica de Chile, Santiago, Chile

3 The School of Psychological Sciences, Tel-Aviv University, Tel Aviv, Israel

4 Department of Psychology, University of Leuven, Leuven, Belgium

5 School of Politics and International Studies, University of Leeds, Leeds, United Kingdom

6 Department of Psychological and Brain Sciences, University of Massachusetts Amherst, Amherst, USA

7 Department of Humanities, University of Ferrara, Ferrara, Italy

8 Institute of Psychology, University of Lausanne, Lausanne, Switzerland

9 Migration, Integration, Transnationalization, Berlin Social Science Center, Berlin, Germany

10 School of Psychology, University of Kent, Kent, United Kingdom

11 School of Psychology, The University of Queensland, Australia

12 Department of Psychology, Singidunum University, Belgrade, Serbia

13 Department of Psychology, Simon Fraser University, Burnaby, Canada

14 Experimental Psychology, University College London, London, United Kingdom

15 Department of Psychology, The New School for Social Research, New York, USA

16 Department of Psychology, ARTIS International, Scottsdale, USA

17 Department of Psychology, Goethe University, Frankfurt, Germany

18 Department of Psychology, University of Belgrade, Belgrade, Serbia

19 Department of Social Psychology, ELTE Eötvös Loránd University, Budapest, Hungary

20 Department of Psychology, University of Granada, Granada, Spain

21 Department of Psychology, University of Monterrey, Monterrey, Mexico

22 Institute of Political Studies, Faculty of Social Sciences, Charles University, Prague,

Czech Republic

23 Faculty of Psychology, University of Warsaw, Warsaw, Poland

24 Department of Psychology, University of Groningen, Groningen, Netherlands

25 Social Sciences Unit, Rochester Institute of Technology in Kosovo, Pristina, Kosovo 
26 School of Psychology, Keele University, Newcastle-under-Lyme, United Kingdom 27 Department of Psychology, Iowa State University, Ames, USA

28 Department of Developmental and Social Psychology, Sapienza University of Rome, Rome, Italy

29 Department of Psychology, University of Zagreb, Zagreb, Croatia

30 Department of Psychology, National Research University Higher School of Economics, Moscow, Russia

31 Department of Psychology, The Pennsylvania State University, University Park, USA 32 Department of Psychology, Columbia University in the City of New York, New York, USA

33 School of Social and Life Sciences, Sheridan College, Oakville, Ontario, Canada

34 Department of Informatics, ETH Zurich, Zurich, Switzerland

35 Department of Psychology, University of Pristina, Pristina, Kosovo

36 Department of Psychology, D’OR Institute for Research and Education, Rio de Janeiro, Brazil.

* Corresponding author: Tabea Hässler (tabea.haessler@uzh.ch). 


\begin{abstract}
Guided by the early findings of social scientists, practitioners have long advocated for greater contact between groups to reduce prejudice and increase social cohesion. Recent work, however, suggests that intergroup contact can undermine support for social change toward greater equality, especially among disadvantaged group members. Using a large and heterogeneous dataset ( $N=12,997$ individuals from 69 countries), we demonstrate that intergroup contact and support for social change toward greater equality are positively associated among members of advantaged groups (ethnic majorities and cis-heterosexuals), but negatively associated among disadvantaged groups (ethnic minorities and sexual and gender minorities). Specification curve analysis revealed important variation in the size-and at times, direction - of correlations, depending on how contact and support for social change were measured. This allowed us to identify one type of support for change, willingness to work in solidarity, that is positively associated with intergroup contact among both advantaged and disadvantaged group members.
\end{abstract}


Since initial efforts toward racial desegregation in the United States, social scientists ${ }^{1}$ policymakers and civic leaders supporting racial desegregation ${ }^{2}$ have advocated for bringing advantaged and disadvantaged group members together for contact with each other in an effort to foster improved relations and greater intergroup equality. Evidence gathered over several decades shows that intergroup contact can reduce prejudice and increase social cohesion across group divides ${ }^{3,4}$. A new line of thinking, however, suggests that contact can have an unintended effect: greater perceptions of intergroup harmony may undermine people's willingness to demand and advocate for greater equality and social justice, especially among members of disadvantaged groups ${ }^{5-8}$. Given the importance of these divergent trends for public policy, comprehensive and rigorous tests are needed to elucidate when contact may be associated with more or less support for social change. This research provides such a test using a large and heterogeneous dataset.

The relation between intergroup contact and support for social change is more nuanced than is typically recognized. Among members of advantaged groups, such as ethnic majorities and cis-heterosexuals (i.e., heterosexuals whose gender identity corresponds to their assigned sex), contact with members of disadvantaged groups, such as ethnic minorities and LGBTIQ+ individuals (i.e., individuals identifying as lesbian, gay, bisexual, transgender, intersexual, queer, and other sexual or gender minorities) is generally — but not invariably_ associated with greater support for intergroup equality and social change ${ }^{9-11}$. Yet, in some cases, contact may improve advantaged group members' feelings toward disadvantaged groups while having little impact on their support for policies or actions designed to redress group-based inequalities ${ }^{12}$.

Among disadvantaged group members, support for social change is generally thought to be motivated by perceived injustice and anger ${ }^{13,14}$. Yet, it is possible that these feelings can be undercut to the extent that contact fosters perceptions of harmonious intergroup relations. 
As a result, intergroup contact may curb disadvantaged group members' motivation to fight for greater equality ${ }^{6,8,9}$. The potential for contact to both promote and undermine support for social change highlights the need for research elucidating when, for whom, and in what contexts intergroup contact predicts people's willingness to advocate and take action for social equality.

In trying to answer this question, it is important to recognize further that the forms, content, and nature that contact can take are as varied as are efforts to achieve social change. To illustrate, members of advantaged and disadvantaged groups may be friends with each other; alternatively, they may only be acquainted with each other, or they simply may know of people from their own group who have contact with people in the other group. Contact might also differ in its valence, ranging from positive to negative in experience. Similarly, action for social change can include a range of activities, such as attending demonstrations, signing petitions, raising peers' awareness of inequality, supporting policies that empower disadvantaged groups, or working in solidarity with other groups. To establish both whether and when contact predicts social change, it is necessary to systematically assess the relationship between these different forms of contact and actions for social change.

However, as is typically the case in social science research, the existing studies have used a wide range of conceptualizations and measures of contact and support for change to assess these constructs. Research also makes use of a wide range of methodologies, analytic approaches, and samples ${ }^{5,9,15}$. While these diverse methods may help to triangulate the overall effects of contact, such variation makes it difficult to provide reliable answers to questions that carry critical implications for public policy. To assess the reliability of a particular finding, and the characteristics of studies that are associated with stronger, weaker, or reversed effects, a study must be repeated across many contexts using comparable measures and analytic procedures. The present research tests for both the reliability of the 
association between contact and support for social change and its potential variability across the many measures and analytic decisions commonly used.

In this multi-national collaboration, all researchers included the same extensive array of commonly used measures of contact and support for social change in assessment (see Table 1). This enabled us to estimate an overall correlation between contact and social change, as well as conditional correlations that arise from different combinations of varied measures assessing contact and social change ${ }^{16-18}$.

$<$ Table 1 about here>

Heeding calls for more collaborative, high-powered, transparent, and reproducible research processes ${ }^{19}$, we test the association between contact and support for social change using a large and heterogeneous dataset, sampling 12,997 participants from 69 countries and four populations (ethnic majorities, cis-heterosexuals, ethnic minorities, and LGBTIQ+ individuals; see Supplementary Tables 1-3 for more details). Note that the term 'ethnic minorities' is used as an umbrella term, denoting groups within a country who are structurally disadvantaged due to their racial, ethnic, national, tribal, religious, or cultural backgrounds; the specific backgrounds of ethnic minority groups are likely to vary across countries, depending on historical patterns of migration and colonization ${ }^{20}$. While a large body of intergroup contact research has focused on racial and ethnic relations, contact between members of LGBTIQ+ communities and cis-heterosexuals has been largely neglected ${ }^{7}$. Including samples of cis-heterosexuals and LGBTIQ+ individuals-who often face direct discrimination by cis-heterosexuals ${ }^{21}$ as well as structural disadvantages ${ }^{22}$-allowed examination of the association between contact and support for social change among disadvantaged and advantaged groups that are consistent across all countries.

The study followed a preregistered analysis plan stored along with the questionnaires, data, and code at: https://osf.io/m5pb6/ (see also Supplementary Table 13). To estimate the 
relation between contact and support for social change, we calculated bivariate correlations after removing the sample means from the data via residualization (which is comparable to a multilevel analysis with random intercepts). Although we expected that contact and support for social change would generally be positively related among advantaged groups (ethnic majorities and cis-heterosexuals) and negatively related among disadvantaged groups (ethnic minorities and LGBTIQ+ individuals), variations in these overall associations are of particular interest. We used specification curve analysis ${ }^{23}$ to probe the variation in the direction and magnitude of the association between contact and social change using every combination of available measures (see Supplementary Figure 3). In addition, we tested the impact of two analytic decisions typically faced by survey researchers: whether to exclude or include statistical outliers and/or participants who failed the attention check. Combining these four model specification factors in a full factorial design (Supplementary Table 7) -5 (support for social change measures) $\times 8$ (contact measures) [6 for LGBTIQ+ individuals for whom we did not assess quantity of contact, see Table 1] $\times 2$ (attention check failures included/excluded) x 2 (outliers included/excluded) — results in 160 model specifications [120 for LGBTIQ+ individuals]. Thus, summing across the four populations, there were 600 opportunities to estimate the correlation between contact and support for social change.

First, we conducted an individual significance test of the Pearson correlation for each single model specification. We performed one-tailed tests using an alpha of .05 in line with our preregistered directional hypotheses.

Next, to test the overall hypothesis that contact predicts social change positively for advantaged groups and negatively for disadvantaged groups, we conducted a joint significance test ${ }^{23}$ (Supplementary Figure 3) for each of the four populations. Considering results of all 160 [120] model specifications for a given population at once, this joint significance test indicates whether the null hypothesis should be rejected (i.e., correlations are 
not different from zero). Using permutation, we determined the likelihood of obtaining the observed number of significant correlations by chance (if the null hypothesis was true) by shuffling the data set 1,000 times. We rejected the null hypothesis when this likelihood was less than .05 . Table 2 shows the key results of the tests of the preregistered hypotheses. According to the joint significance test, the number of significant correlations in the predicted direction clearly exceeded the number expected by chance for all four populations. After adjusting the $p$-values to cap the probability of false discoveries at $5 \%{ }^{24}$, the number of significant correlations was only slightly smaller (cf. numbers in parentheses in Table 2; see also Supplementary Tables 9-10). Thus, we obtained consistent support for the preregistered hypotheses that the correlation between contact and support for social change is positive among ethnic majority group members and cis-heterosexuals and negative among ethnic minority group members and LGBTIQ+ individuals.

$<$ Table 2 about here $>$

To examine in more detail how results varied depending on model specification, we visually inspected the specification curves. Figure 1A shows all results for ethnic majorities. The top of the figure shows the sorted correlations between contact and support for social change, along with confidence intervals for the population value. The bottom of Figure 1A indicates the model specification underlying each correlation. For example, the model specification that produced the largest positive correlation between contact and social change among ethnic majorities (highlighted on the far right of Figure 1A) uses 'working in solidarity' as a measure of support for social change in combination with the measure 'positive contact', excluding participants who failed the attention check and statistical outliers. Figure 1B shows all results for cis-heterosexuals. Visual examination of Figures 1A and 1B reveals that almost all correlations between contact and support for social change were positive among advantaged groups. Moreover, correlations varied considerably 
depending on model specification, ranging from $r=.01$ to $r=.46$ (mean $r=.20$ ) among ethnic majorities and from $r=-.11$ to $r=.43$ (mean $r=.23$ ) among cis-heterosexuals.

Meta-regression (Supplementary Table 8) revealed which measures and analytic decisions produced larger or smaller correlations. The coefficients shown in parentheses in Figures $1 \mathrm{~A}$ and $1 \mathrm{~B}$ represent the predicted change in correlations (relative to the grand mean of correlations) resulting from using one particular measure or analytic decision (see Supplementary Table 8 for individual significance tests).

The effects of using any particular measure of support for social change were similar across both advantaged groups (see cross-validation analyses in Supplementary Table 11). Many of the largest positive correlations between intergroup contact and support for social change include the 'working in solidarity' measure. This means that the predicted positive correlation between contact and support for social change was particularly clear with regard to advantaged group members' willingness to work in solidarity with members of disadvantaged groups. In contrast, model specifications including 'raising ingroup awareness' consistently produced smaller positive correlations. Among measures of contact, 'positive contact' produced larger positive correlations among both ethnic majorities and cisheterosexuals, while patterns of effects for other contact measures were more varied across ethnic majorities and cis-heterosexuals. Finally, both analytic decisions - to include or exclude attention check failures or statistical outliers — had negligible effects on the size of the correlations.

In contrast to the consistent positive correlations observed among advantaged groups, visual examination of Figures 2A and 2B reveals that correlation coefficients ranged from $r=$ -.28 to $r=.21$ (mean $r=-.04$ ) among ethnic minorities and from $r=-.37$ to $r=.15$ (mean $r$ $=-.09)$ among LGBTIQ+ individuals. 
Despite overall support for the predicted negative relation, the specific measure of support for social change used in model specification determined the size and direction of the correlation for both ethnic minorities and LGBTIQ+ individuals. Larger negative correlations between contact and support for social change resulted from model specifications including 'raising ingroup awareness' or 'high cost collective action'. By contrast, positive correlations were almost exclusively produced by model specifications including 'working in solidarity' as the measure of support for social change.

With regard to the contact measures, the most striking results were the strong negative correlations revealed by measures of 'absence of negative contact'. That is, members of disadvantaged groups who reported fewer negative contact experiences (e.g., direct or indirect experiences of derogation and discrimination) reported less support for social change. Also, model specifications including 'number of outgroup friends' as the contact measure produced fairly consistent and significant negative correlations with measures of support for social change. Interestingly, 'positive contact' was positively related to 'working in solidarity' but negatively related to other measures of support for social change. Again, the exclusion of attention check failures and statistical outliers (i.e., analytic decisions) had negligible effects on the size of the correlations. Cross-validation analyses (Supplementary Table 11) confirmed that there were highly similar patterns of results among ethnic minorities and LGBTIQ+ individuals, indicating robustness and generalizability.

In summary, the confirmatory analyses support the preregistered hypotheses that intergroup contact and support for social change tow ard greater equality are positively associated among members of advantaged groups (ethnic majorities and cis-heterosexuals), but negatively associated among disadvantaged groups (ethnic minorities and LGBTIQ+ individuals). However, the multifaceted analyses presented here, involving 600 tests of the 
association between contact and support for social change, put into perspective potential concerns associated with intergroup contact.

Overall, the more ethnic minorities and LGBTIQ+ individuals experience positive and intimate intergroup contact (e.g., friendships), or lack negative intergroup contact experiences, the less inclined they are to support efforts for social change. These findings are consistent with research showing that contact between members of different groups-which is experienced as positive in valence yet does not address structural inequalities — can decrease anger ${ }^{25}$, distract attention away from group-based inequality ${ }^{6,7}$, and decrease identification with the disadvantaged ingroup ${ }^{8,25}$. All these factors can reduce support for social change among members of disadvantaged groups $7,8,14,26,27$.

However, among both advantaged and disadvantaged groups, contact was positively associated with one particular form of support for social change: working in solidarity toward social change. The more contact that occurs between advantaged and disadvantaged group members, and the more positively this contact is experienced, the more willing members of both groups are to collaborate in efforts to achieve greater social equality. This finding is unique, and the 'working in solidarity' measure captures a pathway to social change that is increasingly observed (e.g., LGBTIQ+/straight alliances) ${ }^{28}$ but has been largely overlooked in prior research on the relation between contact and social change. Moreover, the "working in solidarity' measure taps both support for social change and positive orientations toward collaborating with outgroup members to enact such change. Given other findings we report in this paper, it is possible that these two elements may be seen or valued differently by members of advantaged and disadvantaged groups. Among advantaged groups, willingness to work in solidarity might reflect a recognition that social change is the responsibility of many in the larger society as a whole, rather than a burden to be carried solely by members of disadvantaged groups ${ }^{29,30}$. At the same time, it is not entirely clear the extent to which 
members of disadvantaged groups who endorse this measure actually desire social change on top of achieving the positive intergroup relations implied by the solidarity concept. Such questions offer intriguing directions for future research.

Nonetheless, the present results suggest some inherent difficulties in leveraging solidarity for social change among advantaged and disadvantaged groups. The positive association between contact and working in solidarity coexists with the negative association between contact and engagement in high cost collective action and raising ingroup awareness among members of disadvantaged groups. If, through contact with the advantaged, disadvantaged group members become less inclined to raise awareness about inequalities or engage in public protest and/or other more direct efforts to produce social change, solidarity of advantaged group members would lack meaningful routes for deployment.

Thus, our results pose two major questions for future research. How can positive and intimate contact between groups occur without reducing disadvantaged group members' support for social change? And how can support for social change be bolstered among disadvantaged group members without requiring negative contact experiences? Possible answers to both questions involve having advantaged group members openly acknowledge structural inequalities and express support for efforts to reduce these inequalities during contact with disadvantaged groups ${ }^{31,32}$. For efforts to promote and support social change to succeed, it seems essential that contact between advantaged and disadvantaged groups is not simply experienced as pleasant, but that it prepares members of both groups to address structural inequalities.

Although this research advances our understanding of the relation between intergroup contact and social change, a limitation is that our design cannot support causal conclusions. Future research would benefit from longitudinal designs to this end ${ }^{10}$. Also, in the interest of a succinct presentation, we set aside potentially interesting variance across contexts (e.g., due 
to institutional policies ${ }^{33}$ ). Nevertheless, a clear strength of the present research is the robust evidence it provides that members of advantaged groups with more frequent, positive, and intimate forms of intergroup contact reported greater support for social change, while such forms of contact were associated with less support for social change among members of disadvantaged groups. There is, however, an important exception: Among both advantaged and disadvantaged groups, contact predicted greater willingness to work in solidarity to achieve greater social equality. This finding offers a new, understudied route to reach social cohesion and social change, such that social harmony would not come at the expense of social justice. 


\section{Methods}

We planned to collect 64 samples with at least 100 participants each (see preregistration). Due to widespread dissemination of the link to the survey, individuals from additional countries participated in the survey (see also Supplementary Table 13). Therefore, this project sampled a total of 12,997 participants from four populations (ethnic majorities, cis-heterosexuals, ethnic minorities, and LGBTIQ+ individuals). We administered surveys in 69 countries (including several non-Western, educated, industrialized, rich, or democratic countries $)^{34}$. Our total sample includes 3,216 ethnic majority group members (1,040 male, 2,162 female, 14 other, $\left.M_{\text {age }}=28.08, S D_{\text {age }}=11.28\right), 4,898$ cis-heterosexuals $(1,575$ male, 3,323 female, $\left.M_{\text {age }}=29.47, S D_{a g e}=12.84\right), 1,000$ ethnic minority group members (412 male, 585 female, 1 other, $\left.2 \mathrm{NA}, M_{\mathrm{age}}=29.15, S D_{\text {age }}=11.13\right)$, and 3,883 LGBTIQ+ individuals $\left(1,445\right.$ male, 2,061 female, 377 other, $\left.M_{\text {age }}=30.42, S D_{a g e}=12.53\right)($ see Supplementary Figure 1 for inclusion criteria; Supplementary Tables 1-3 for more details).

\section{Ethical Review}

According to the checklist of the Ethics Committee of the Faculty of Arts and Social Sciences at the University of Zurich, this research fulfils the guidelines of the American Psychological Association and the Swiss Psychological Society, meaning that no formal approval was necessary. Additionally, several researchers or research teams have obtained approval from their local ethics committee if their institutions required them to do so (Eötvös Loránd University, Budapest, 236/2016; University of Massachusetts Amherst, 2015-2460; University of Leuven, G-2016 02 488; Pontificia Universidad Católica de Chile, 160323010; University of Kent, 20163785; Tel Aviv University; Simon Fraser University, 2016s0473).

\section{Analytic Procedure}

First, we regressed the original items on the subsample identifier variable to obtain residualized item scores. This was done to ensure that we would test the association of 
contact and support for social change at the level of individuals rather than at the level of subsamples or countries. Next, we conducted confirmatory factor analyses (CFA) to select the final set of items and scales (all steps of the CFAs can be reproduced with the file Scale_Construction_CFA.R). CFA justified using the same eight contact scales and five support for social change scales for all four populations except for contact reported by LGBTIQ+ individuals where we used only six contact scales (Table 1, see Supplementary Table 4 for a detailed overview and Supplementary Tables 5 and 6 for descriptive statistics). Finally, to estimate the bivariate correlations between intergroup contact and support for social change conditional on methodological choices, we conducted specification curve analyses following Simonsohn and colleagues' procedure (2015). Supplementary Figure 2 gives an overview of the procedure. Please note that we also ran additional specification curve analysis controlling for age, gender, and socioeconomic status; the conclusions remain unchanged when these controls are included (see Supplementary Table 12 and Supplementary Figures 4 and 5). Please note also that our conclusions do not depend on using Pearson correlations. Alternative analyses using Spearman correlations, which do not rely on the assumption of normality, produced highly similar results.

All steps of the specification curve analysis can be reproduced with the Master_Script.R and the underlying Functions.R script. 


\section{Data Availability}

Data underlying the analyses reported in the paper have been deposited on the Open Science Framework under the following link https://osf.io/wgdhb/. 


\section{Code Availability}

$\mathrm{R}$ code and scripts to reproduce the analyses presented in the manuscript. This code can be found on the Open Science Framework at: https://osf.io/8rcz9/ 


\section{References}

1. Allport, G. W. The nature of prejudice. (Reading, MA: Addison-Wesley, 1954)

2. Schofield, J. W. (1991). School Desegregation and Intergroup Relations: A Review of the Literature. Review of research in education, 17, 335-409 (1991).

3. Lemmer, G., \& Wagner, U. Can we really reduce ethnic prejudice outside the lab? A meta-analysis of direct and indirect contact interventions. European Journal of Social Psychology, 4, 152-168 (2015).

4. Pettigrew, T. F., \& Tropp, L. R. A meta-analytic test of intergroup contact theory. Journal of Personality and Social Psychology, 90, 751-783 (2006).

5. Çakal, H., Hewstone, M., Schwär, G., \& Heath, A. An investigation of the social identity model of collective action and the 'sedative' effect of intergroup contact among Black and White students in South Africa. British Journal of Social Psychology, 50, 606-627 (2011).

6. Dixon, J., Durrheim, K., \& Tredoux, C. Intergroup contact and attitudes toward the principle and practice of racial equality. Psychological Science, 18, 867-872 (2007).

7. Saguy, T., Tausch, N., Dovidio, J. F., \& Pratto, F. The irony of harmony: Intergroup contact can produce false expectations for equality. Psychological Science, 20, 114121 (2009).

8. Wright, S. C., \& Lubensky, M. E. The struggle for social equality: Collective action versus prejudice reduction. In S. Demoulin, J.-P. Leyens, J. F. Dovidio (Eds.). Intergroup misunderstandings: Impact of divergent social realities (pp. 291-310). (New York, NY, US: Psychology Press., 2009).

9. Kamberi, E., Martinovic, B., \& Verkuyten, M. Intergroup contact and minority group empowerment: The perspective of Roma and non-Roma adolescents in Macedonia. Journal of Community \& Applied Social Psychology, 27, 424-434 (2017). 
10. Reimer, N. K. et al. Intergroup contact and social change. Personality and Social Psychology Bulletin, 4, 121-136 (2017).

11. Tropp, L. R., \& Barlow, F. K. Making advantaged racial groups care about racial inequality: Intergroup contact as a route to psychological investment. Current Directions in Psychological Science, 27, 194-199 (2018).

12. Jackman, M. R., \& Crane, M. "Some of my best friends are Black": Interracial friendship and Whites' racial attitudes. Public Opinion Quarterly, 50, 459-486 (1986).

13. Van Stekelenburg, J., \& Klandermans, B. The social psychology of protest. Current Sociology, 61, 886-905 (2013).

14. Van Zomeren, M., Postmes, T., \& Spears, R. Toward an integrative social identity model of collective action: A quantitative research synthesis of three sociopsychological perspectives. Psychological Bulletin, 134, 504-535 (2008).

15. Droogendyk, L., Louis, W. R., \& Wright, S. C. Renewed promise for positive crossgroup contact: The role of supportive contact in empowering collective action. Canadian Journal of Behavioural Science/Revue Canadienne des Sciences du Comportement, 48, 317-327 (2016).

16. Patel, C. J., Burford, B., \& Ioannidis, J. P. A. Assessment of vibration of effects due to model specification can demonstrate the instability of observational associations. Journal of Clinical Epidemiology, 68, 1046-1058 (2015).

17. Rubin, D. Meta-analysis: Literature synthesis or effect-size surface estimation? Journal of Educational Statistics, 17, 363-374 (1992).

18. Steegen, S., Tuerlinckx, F., Gelman, A., \& Vanpaemel, W. Increasing transparency through a multiverse analysis. Perspectives on Psychological Science, 11, 702-712 (2016). 
19. Nosek, B. A. et al. Promoting an open research culture. Science, 348, 1422-1425 (2015).

20. Alba, R., \& Foner, N. Strangers no more: Immigration and the challenges of integration in North America and Western Europe. (Princeton University Press, 2015).

21. Herek, G. M., \& McLemore, K. A. Sexual prejudice. Annual Review of Psychology, 64, 309-333 (2013).

22. United Nations Human Rights Council. Discrimination and violence against individuals based on their sexual orientation and gender identity. Retrieved from http://www.refworld.org/docid/5571577c4.html (2015).

23. Simonsohn, U., Simmons, J. P., \& Nelson, L. D. Specification curve: Descriptive and inferential statistics on all reasonable specifications. Preprint at http://papers.ssrn.com/sol3/papers.cfm?abstract_id=2694998 (2015).

24. Benjamini, Y., \& Yekutieli, D. The control of the false discovery rate in multiple testing under dependency. The Annals of Statistics, 29, 1165-1188 (2001).

25. Tausch, N., Saguy, T., \& Bryson, J. How does intergroup contact affect social change? Its impact on collective action and individual mobility intentions among members of a disadvantaged group. Journal of Social Issues, 71, 536-553 (2015).

26. Ufkes, E. G., Dovidio, J. F., \& Tel, G. Identity and collective action among European Kurds. The British Journal of Social Psychology, 54 (2015).

27. Saguy, T. Downside of intergroup harmony?: When reconciliation might backfire and what to do. Policy Insights from the Behavioral and Brain Sciences, 5, 75-81 (2018).

28. Fingerhut, A. W. Straight Allies: What Predicts Heterosexuals' Alliance With the LGBT Community? 1. Journal of Applied Social Psychology, 41, 2230-2248 (2011).

29. Subašić, E., Reynolds, K. J., \& Turner, J. C. The political solidarity model of social 
change: Dynamics of self-categorization in intergroup power relations. Personality and Social Psychology Review, 12, 330-352 (2008).

30. Pettigrew, T. F., \& Hewstone, M. The single factor fallacy: Implications of missing critical variables from an analysis of intergroup contact theory. Social Issues and Policy Review, 11, 8-37 (2017).

31. Becker, J.C., Wright, S.C., Lubensky, M.E., \& Zhou, S. Friend or ally: Whether cross-group contact undermines collective action depends what advantaged group members say (or don’t say). Personality and Social Psychology Bulletin, 39, 442-455 (2013).

32. Droogendyk, L., Wright, S. C., Lubensky, M., \& Louis, W. R. Acting in solidarity: Cross-group contact between disadvantaged group members and advantaged group allies. Journal of Social Issues, 72, 315-334 (2016).

33. Tankard, M.E., \& Paluck, E.L. The effect of a Supreme Court decision regarding Gay Marriage on social norms and personal attitudes. Psychological Science, 28, 13341344 (2017).

34. Henrich, J., Heine, S. J., \& Norenzayan, A. The weirdest people in the world? Behavioural and Brain Sciences, 33, 61-135 (2010). 


\section{Acknowledgments}

This project received direct financial support through the Swiss Bilateral Program of the State Secretariat for Education, Research and Innovation (SERI) awarded to Johannes Ullrich, Robert González, Tabea Hässler, Michelle Bernadino, and Daniel Valdenegro. The Chilean research team was supported by Fondecyt (1161371), the Center for Social Conflict and Cohesion Studies (FONDAP 15130009), and the Center for Intercultural and Indigenous Research (FONDAP 15110006) awarded to Roberto González. The Dutch part of this research was funded by FWO Odysseus grant (G.O.E66.14N) awarded to Colette van Laar. The English part of this research was funded by a grant from the ESRC commissioning (403006662) awarded to Dominic Abrams and Giovanni Travaglino. Stephen Wright was funded by a grant from the Social Science \& Humanities Research Council of Canada. Iris Žeželj was funded by the Serbian ministry of education, science and technological development (179018). The Polish part of this research was funded by the Foundation for Polish Science (TEAM), co-financed by the EU ERDF ("Language as a Cure" Project) awarded to Michal Bilewicz and Olga Kuzawinska. Evgeny Osin was supported by the HSE University Basic Research Program and the Russian Academic Excellence Project '5-100'. The funders had no role in study design, data collection and analysis, decision to publish or preparation of the manuscript.

We thank Luisa Liekefett, Dogan Kokdemir, Dana Indreica, Ana Figueiredo, Neela Mühlemann, and Yasin Koc for their additional help with the translation and/or data collection. We also thank Jeremy Ginges and Léïla Eisner for their insightful comments. Finally, we thank the SoSci Panel, PlanetRomeo, East meets West, Psychologie Heute, and all other LGBTIQ+ organizations for distributing our survey. 


\section{Author Contributions}

Primary idea: T.H. and J.U. Conceptualization of the project and acquisition of the seed money: T.H., J.U., M.B., D.V., and R.G. Creation of research design/instrument construction: T.H., J.U., M.B., D.V., N.S., C.V.L., S.S., E. P. V., L.T., R.G., R.D., D.A., H.S., J.Z., and A.A. Draft of preregistration: T.H., J.U., M.B., and D.V. Coordination of the project: T.H. and J.U. Data collection: All authors collected at least 100 participants. Data preparation: T.H. and S.S. Data analysis: A.G., J.U., T.H., and S.S. Paper draft: T.H. and J.U., supported by S.S. Revision: C.V.L., N.S., L.T., E. P. V., M.B., D.V., R.D., S.W., H.S., M.P., M.B., R.G., D.A., supported by A.K., E.M., J.Z., I.Z., N.L., M.N., J.P., M.S., A.A., M.B., R.B., P.G., S.O., O.B., and E.O. Final editing: L.T.

\section{Competing interests}

The authors declare no competing interests. 


\section{Figure Legends}

\section{Figure 1. Results of the specification-curve analysis among advantaged groups.}

(A) Results of the specification-curve analysis showing the correlation between intergroup contact and support for social change among ethnic majorities $(n=3,216)$.

(B) Results of the specification-curve analysis showing the correlation between intergroup contact and support for social change among cis-heterosexuals $(n=4,898)$.

Note: The top part of Figures 1A and 1B shows sorted correlations and 90\% (95\%) confidence intervals in light (dark) red. The bottom part shows the combinations of measures and analytic decisions underlying each correlation. The numbers in parentheses on the lefthand side indicate the change in size of the correlations (relative to the grand mean of correlations) resulting from using this particular measure or analytic decision.

\section{Figure 2. Results of the specification-curve analysis among disadvantaged groups.}

(A) Results of the specification-curve analysis showing the correlation between intergroup contact and support for social change among ethnic minorities $(n=1,000)$.

(B) Results of the specification-curve analysis showing the correlation between intergroup contact and support for social change among LGBTIQ+ individuals $(n=3,883)$.

Note: The top part of Figures 1A and 1B shows sorted correlations and 90\% (95\%) confidence intervals in light (dark) red. The bottom part shows the combinations of measures and analytic decisions underlying each correlation. The numbers in parentheses on the lefthand side indicate the change in size of the correlations (relative to the grand mean of correlations) resulting from using this particular measure or analytic decision. 


\section{Tables}

Table 1

Overview of Constructs, Measures, and Example Items

\begin{tabular}{|c|c|}
\hline Construct: & INTERGROUP CONTACT \\
\hline Measures: & Example Items: \\
\hline 1) Quantity of contact $\uparrow$ & $\begin{array}{l}\text { How many [outgroup] people do you know, at least as } \\
\text { acquaintances? }\end{array}$ \\
\hline 2) Positive contact & $\begin{array}{l}\text { When you interact with [outgroup], to what extent do } \\
\text { you experience the following: The contact is friendly? }\end{array}$ \\
\hline $\begin{array}{l}\text { 3) Absence of negative } \\
\text { contact }\end{array}$ & $\begin{array}{l}\text { When you interact with [outgroup], to what extent do } \\
\text { you experience the following: The contact is } \\
\text { unfriendly? (recoded) }\end{array}$ \\
\hline $\begin{array}{l}\text { 4) Number of outgroup } \\
\text { friends }\end{array}$ & How many of your friends are [outgroup]? \\
\hline $\begin{array}{l}\text { 5) Frequency of meeting } \\
\text { outgroup friends }\end{array}$ & How often do you meet your [outgroup] friends? \\
\hline $\begin{array}{l}\text { 6) Quantity of indirect } \\
\text { outgroup friends } \dagger\end{array}$ & $\begin{array}{l}\text { As far as you are aware, how many of your [ingroup }{ }^{3} \text { ] } \\
\text { friends or close relatives have [outgroup] friends? }\end{array}$ \\
\hline 7) Positive indirect contact & $\begin{array}{l}\text { As far as you are aware, how many of your [ingroup] } \\
\text { friends or close relatives have had good experiences } \\
\text { with [outgroup] members? }\end{array}$ \\
\hline $\begin{array}{l}\text { 8) Absence of negative } \\
\text { indirect contact }\end{array}$ & $\begin{array}{l}\text { As far as you are aware, how many of your [ingroup] } \\
\text { friends or close relatives have had bad experiences with } \\
\text { [outgroup] members, like tensions or conflict? } \\
\text { (recoded) }\end{array}$ \\
\hline
\end{tabular}

\section{Construct:}

Measures:

1) Low cost collective action

2) High cost collective action

3) Support for empowering policies

4) Raising ingroup awareness

5) Working in solidarity

\section{SUPPORT FOR SOCIAL CHANGE}

\section{Example Items:}

Signing an online/regular petition to support action against the unequal treatment of [disadvantaged group]. Attending demonstrations, protests or rallies against the unequal treatment of [disadvantaged group].

[Disadvantaged group] should obtain much more power in the decision-centers of our society.

When I come into contact with ingroup members, we talk about injustices in society regarding [disadvantaged group].

How willing are you to unite with [outgroup] to work for justice for [disadvantaged group]?

Note: Appropriate names for ingroup, outgroup, and disadvantaged group were inserted in each context. †Quantity of contact and quantity of indirect outgroup friends were not included among LGBTIQ+ individuals because almost every LGBTIQ+ individual has more cis-heterosexual friends than 10 (i.e., the highest scale value) or LGBTIQ+ friends who have more than 10 cis-heterosexual friends. 
Table 2

Tests of Preregistered Hypotheses

\begin{tabular}{lcccc}
\hline Population & $\begin{array}{c}\text { Sample } \\
\text { size }\end{array}$ & $\begin{array}{c}\text { Number } \\
\text { of tests }\end{array}$ & $\begin{array}{c}\text { Number of significant results in } \\
\text { predicted direction }\end{array}$ & $p$-value ${ }^{2}$ \\
\hline Ethnic Majorities & 3,216 & 160 & $158(154)$ & $<.001$ \\
Cis-Heterosexuals & 4,898 & 160 & $149(145)$ & $<.001$ \\
Ethnic Minorities & 1,000 & 160 & $64(52)$ & $<.001$ \\
LGBTIQ+ Individuals & 3,883 & 120 & $86(84)$ & $<.001$ \\
\hline
\end{tabular}

Note: ${ }^{1}$ The number in parentheses indicates the number of significant results after adjusting the p-values using the Benjamini-Yekutieli procedure so that the false discovery rate is at most $5 \% ;{ }^{2} p$-values correspond to the number of shuffled datasets with as many or more significant correlations than in the original data set divided by the total number of shuffled datasets (i.e., 1,000). The smallest possible $p$-value with 1,000 reshuffled samples is $p<$ $1 / 1,000$. 


\section{Supplementary Information}

\section{Supplementary Materials:}

Supplementary Materials and Methods, Supplementary Figures 1-5, Supplementary Tables 113, Supplementary References. 